IAN SNEDDON: TOPICAL FLUORINATED CORTICOSTEROIDS IN ROSACEA

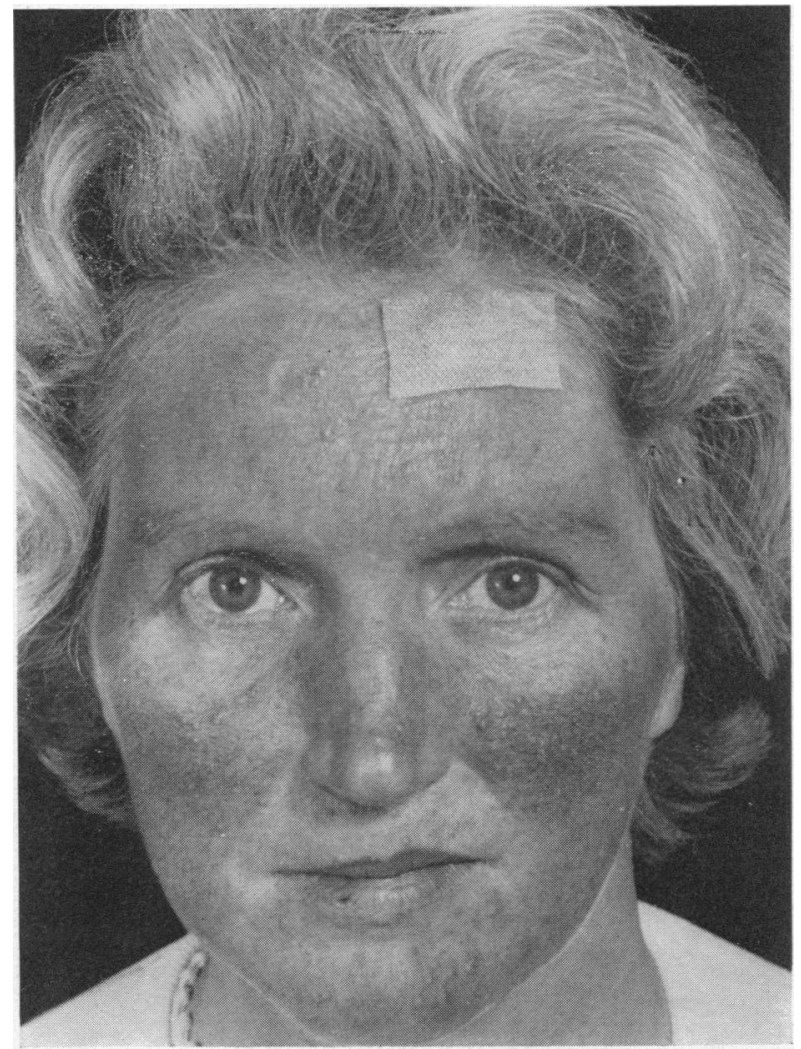

FIG. 1.-Case 2. Photograph showing the eruption of rosacea with telangiectasia extending to the hair margin, 10 August 1968.

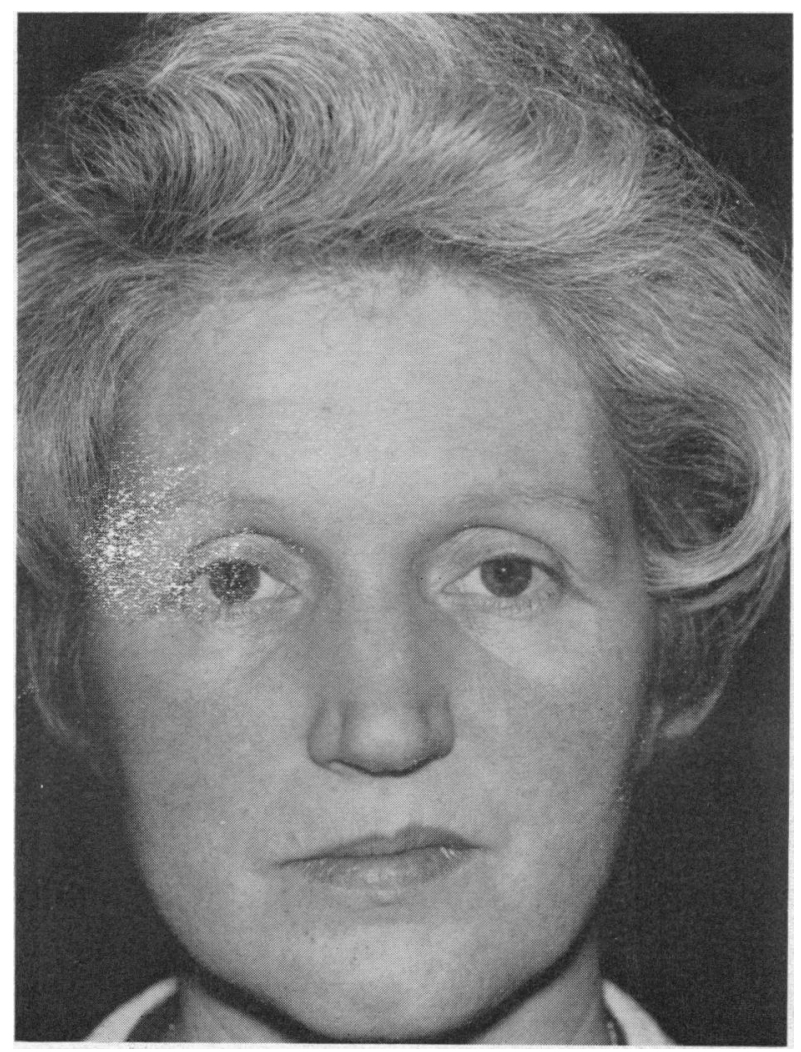

FIG. 3.-Case 2. Photograph taken after treatment, showing almost complete recovery, 2 January 1969.
FIG. 2. - Case 2. Details of left cheek showing telangiectasia, papules, and downy hair growth,

10 August 1968.

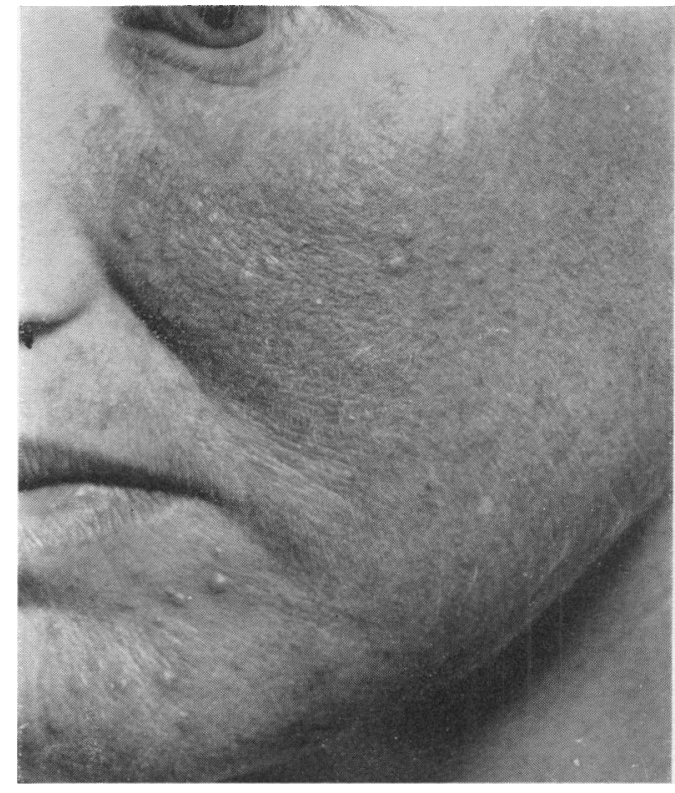

FIG. 4. - Case 2.

Left cheek, showing

only faint telangi-

ment, 2 January
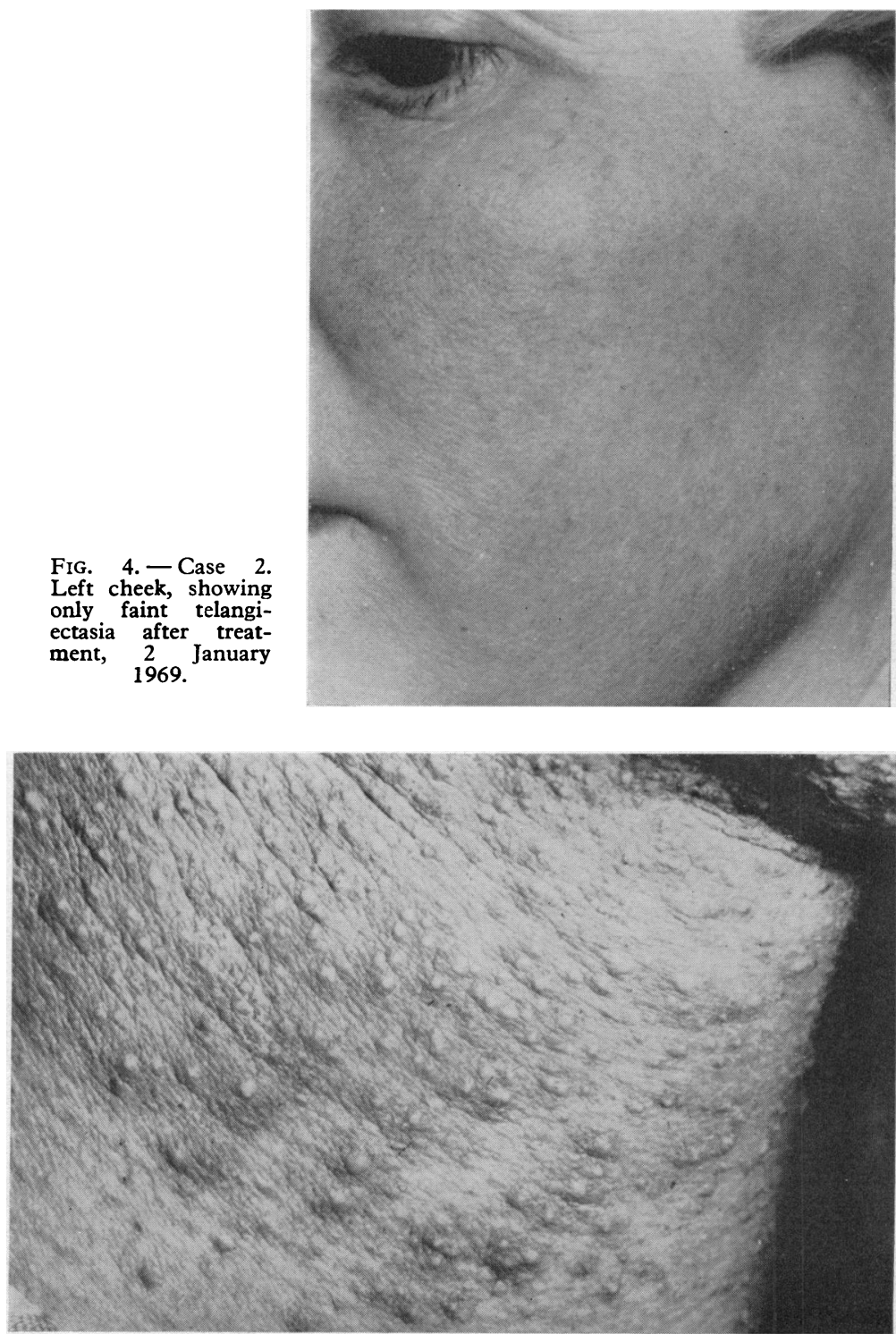

.

FIG. 5.-Case 3. Side of neck showing the profuse pustulation a week after withdrawal of fluocinolone ointment. 
IAN SNEDDON: TOPICAL FLUORINATED CORTICOSTEROIDS IN ROSACEA
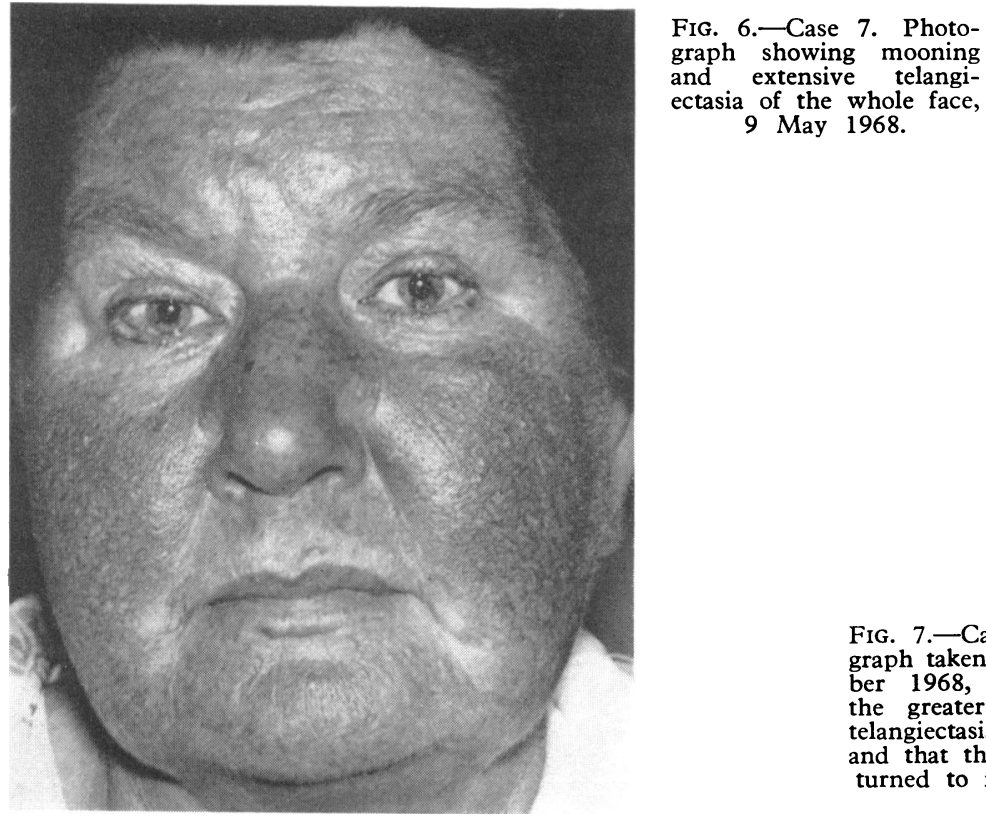

ectasia of the whole face,

9 May 1968.

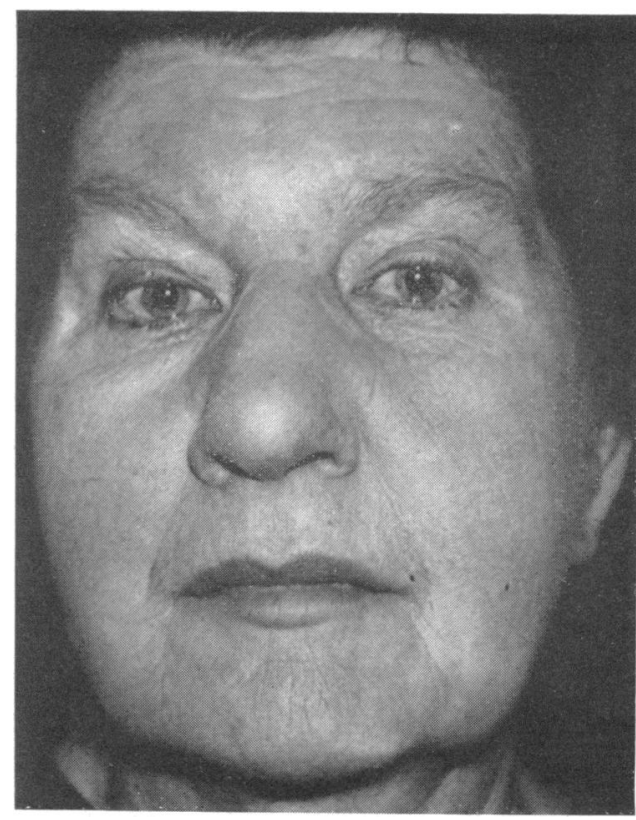

N. H. DYER ET $A L$. : OBSTRUCTION OF BOWEL DUE TO LESION IN THE MYENTERIC PLEXUS

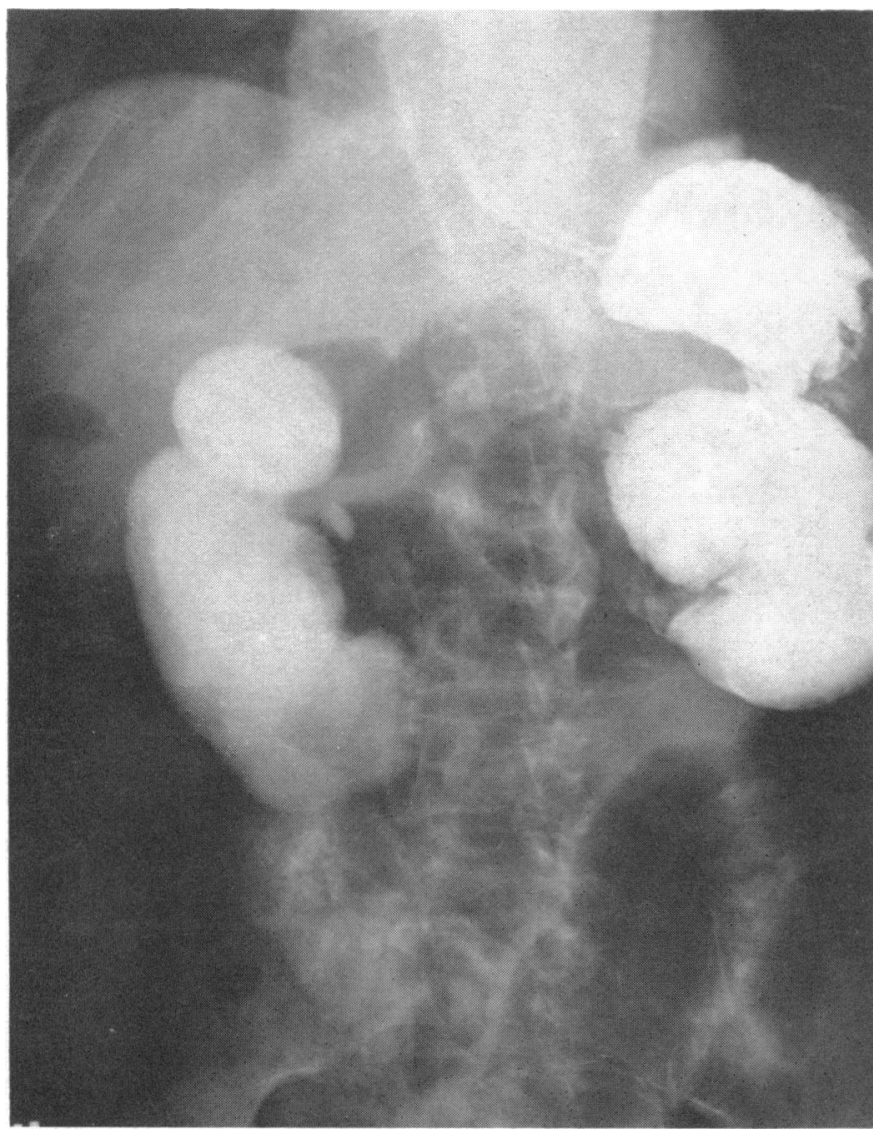

FIG. 1

Fig. 1.-Case 1. Seven-hour film. Gross stasis of barium in fundus of stomach, efferent loop of jejunum, and second part of duodenum. Marked dilatation of duodenum and jejunum.

Fig. 2.-Normal ileum. Note number and size of neurones, delicate regular processes, and absence of Schwann cells in background. ( $\times 240$.)

FIG. 3.-Case 1. Jejunum. Solitary enlarged neurone. Scanty thickened processes. Note branching, irregularity, and fragmentation of processes. Marked increase of Schwann cells in background. Similar changes were seen in Case 2. $(\times 240$.

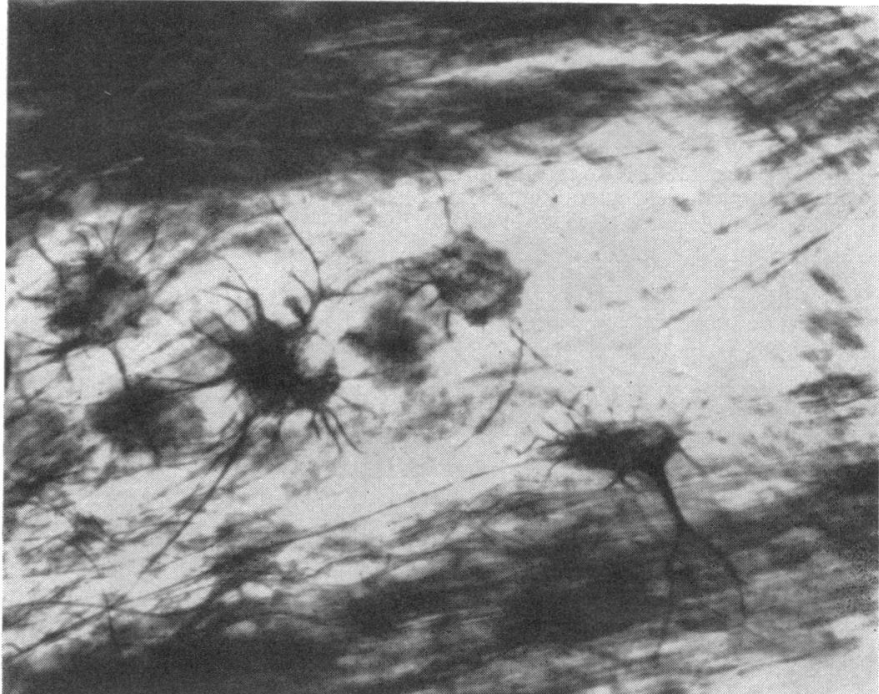

FIG. 2

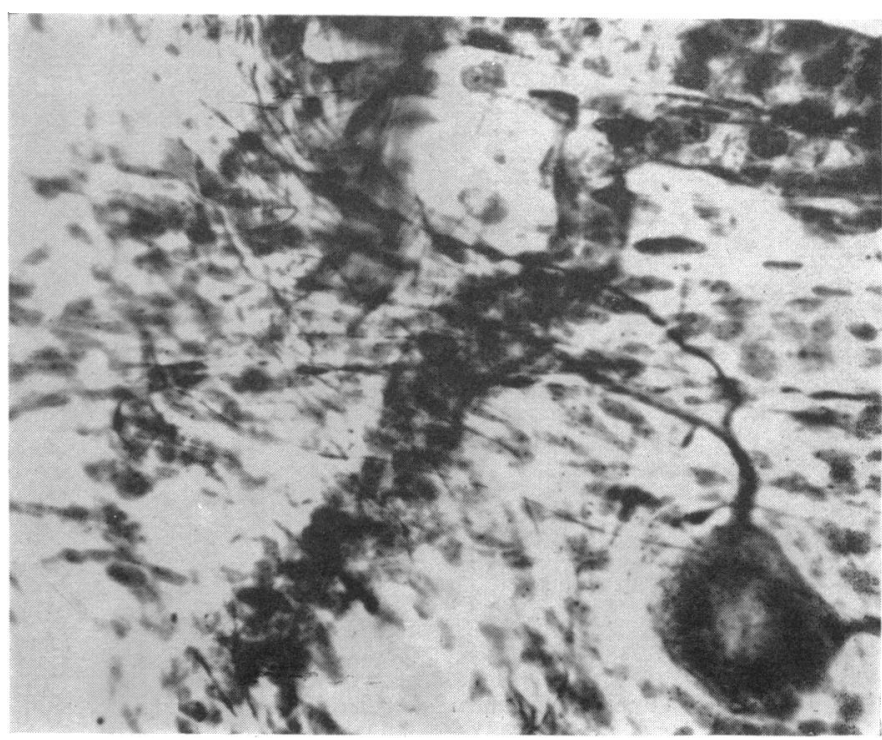

FIG. 3 
Fernbach, D. J., Sutow, W. W., Thurman, W. G., and Vietti, T. J. (1962). F. Amer. med. Ass., 182, 30.

Fox, M. (1964). Transplantation, 2, 475.

Fox, M. (1964). Transplantation, 2, 47.

Graenberg, L. H., and Tanáka, K. R. (1964). F. Amer. med. Ass., 188, 423.

Grupe, W. E., and Heymann, W. (1966). Amer. f. Dis. Child., 112, 448 Heymann, W. (1961). F. Pediat., 58, 609.

Joachim, G. R., Cameron, J. S., Schwartz, M., and Becker, E. L. (1964). 7. clin. Invest., 43, 2332.

Lagrue, G., Bariéty, J., Canlorbe, P., Vassal, J., and Milliez, P. (1967). Presse méd., 75, 1773 .
Marazzini, F., and Macchi, L. (1966). Ann. Obstet. Ginec., 88, 825.

Ogg, C. S., Cameron, J. S., and White, R. H. R. (1968). Lancet, 2, 78. Page, A. R., Condie, R. M., and Good, R. A. (1962). Amer. F. Path. $40,519$.

Rubin, J. S., and Rubin, R. T. (1966). 7. Urol. (Baltimore), 96, 313.

Russell, P. J., and Hicks, J. D. (1968). Lancet, 1, 440.

Russell, P. J., Hicks, J. D., and Burnet, F. M. (1966). Lancet, 1, 1279.

Sharpstone, P., Ogg, C. S., and Cameron, J. S. (1969). In preparation.

West, C. D., Hong, R., and Holland, N. H. (1966). F. Pediat., 68, 516.

White, R. H. R. (1967). Proc. roy. Soc. Med., 60, 1164.

White, R. H. R., Cameron, J. S., and Trounce, J. R. (1966). Brit. med. 7., 2,853 .

\title{
Adverse Effect of Topical Fluorinated Corticosteroids in Rosacea
}

\author{
IAN SNEDDON,* M.B.: F.R.C.P.
}

[With Special Plate facing Page 670]

Brit. med. F., 1969, 1, 671-673

\begin{abstract}
Summary : Fourteen patients suffering from rosacea treated by prolonged topical applications of fluorinated steroids showed adverse effects. Aggravation and extension of telangiectasia occurred in all, and in most cessation of the treatment was followed by severe rebound inflammatory oedema and acute pustular eruption. The telangiectasia cleared or was much improved within three months of cessation of the use of fluorinated steroids. Hydrocortisone did not produce the same effect, and hence it was used, together with oral tetracycline, for treatment.
\end{abstract}

\section{Introduction}

Corticosteroid applications have been so successful in the control of inflammatory reactions of the skin that they are now widely used as a panacea for all dermatoses, but only rarely do undesirable effects occur. Last year I drew attention to an unusual adverse effect of the more potent steroid creams, when used in the treatment of rosacea (Sneddon, 1968). It appeared that prolonged use did suppress pustule formation but increased the telangiectatic appearance of the skin. If the local applications were stopped the pustules recurred rapidly, of ten accompanied by oedema of the face. Many patients resumed treatment to suppress this undesirable effect and thus became virtually dependent, being frightened to stop using the preparations. The appearance of rosacea treated with Betnovate (betamethasone 17-valerate) and Synalar (fluocinolone acetonide) has become a familiar sight, and it is the object of this paper to describe the clinical features and response to treatment of 14 patients seen in the past year.

\section{Case 1}

A 46-year-old housewife complained of a burning and redness of the face of three years' duration. The eruption, which was pustular at the onset, was rapidly controlled by betamethasone ointment that she had applied twice daily for the whole three years. In recent months the skin had become tender, and bleeding followed brisk rubbing with a towel. Examination in January 1968 showed a diffuse erythema and telangiectasia over the whole face right up to the hair margin. It extended far more peripherally than rosacea usually does. The facial skin appeared thinned, atrophic,

* Physician, Rupert Hallam Department of Dermatology, Royal Infirmary, Sheffield. and felt somewhat velvety; a number of small subcutaneous haemorrhages similar to senile purpura were present on the forehead and cheeks. Tetracycline $250 \mathrm{mg}$. twice daily was prescribed and ung. aquosum substituted for the ung. betamethasone. A week later her face became painful and oedematous, but she was encouraged not to resume the betamethasone and to persist with the treatment advised. Tetracycline was continued in a dose of $250 \mathrm{mg}$. twice daily for two months and once daily for a further three months, at the end of which time the facial skin appeared normal.

\section{Case 2}

A housewife aged 40 had treated a facial rash for six years with ung. fluocinolone applied daily. She had tried to stop using it, but the rash, consisting of pustules, recurred within a few days and she felt compelled to use the application again. When first seen in 1968 she showed skin-coloured papules over the forehead, cheeks, and chin, characteristically the abortive papulo-pustules of rosacea, and extensive telangiectasia over the whole forehead, cheeks, and chin. There was a fine downy growth of hair, particularly on the cheeks. The skin appeared thinned, and a number of subcutaneous haemorrhages were present. The eruption was confined to the face and ceased below the angle of the jaw (Special Plate, Figs. 1 and 2). A biopsy specimen taken from the forehead showed normal epidermis. In the dermis sebaceous glands were prominent and surrounded by inflammatory cells, and, in addition, the dermal collagen showed basophilic degeneration with heavy positivity on elastic staining. Dermal vessels were prominent and dilated. The appearances were those of acne rosacea with dermal atrophy.

She was treated with tetracycline $250 \mathrm{mg}$. twice daily for one month and then once daily for a further three months, by which time her face appeared normal (Special Plate, Figs. 3 and 4). During the first two weeks of treatment she complained bitterly that her face had become more painful and swollen. Hydrocortisone ointment was prescribed as a substitute for the fluocinolone, as experience had shown that this did not perpetuate the atrophy.

\section{Case 3}

A 34-year-old married bus conductress had controlled a facial eruption with betamethasone ointment for five years. The eruption was described as erythematous with recurrent pustulation. As her face had become more and more telangiectatic she was referred to the dermatological department, where she was seen in March 1968 and advised to stop using the betamethasone ointment. She was admitted to hospital seven days later because the whole of her face and neck had become red, swollen, and covered with pustules, 2 to $3 \mathrm{~mm}$. in diameter. The pustules extended over the whole face to the hair margin, down the sides of the neck, and on to the pinnae 
(Special Plate, Fig. 5). Her condition continued to worsen for 10 days after admission despite the application of soothing lotions and tetracycline $250 \mathrm{mg}$. b.d. Throughout the whole time she was not pyrexial. Improvement then slowly occurred and she was discharged home after 18 days. A month later, tetracycline having been continued, her face was clear of pustules. Improvement was maintained and she made a complete recovery.

\section{Case 4}

A 47-year-old schoolmistress was first seen in November 1962 with rosacea, which had apparently been started by an emotional family upset six months previously. As she did not respond to lotio sulphurata and superficial $x$-ray therapy, a recognized treatment for rosacea at that time, fluocinolone ointment was prescribed with gratifying results. She continued to apply the ointment until May 1963, when calamine lotion was substituted, and she developed a severe pustular eruption on the face and neck, which necessitated admission to hospital, as she was so emotionally disturbed. Fluocinolone ointment was again prescribed, and she improved. She continued to apply fluocinolone ointment almost daily until she forgot to take it on holiday in June 1967. A sudden severe pustular eruption developed on her face and neck, which was at the time ascribed to sunlight aggravation, and she was again admitted to hospital. Culture of pustules showed only coagulase-negative staphylococci, and apart from a slight iron-deficiency anaemia no other abnormality was found. She was treated with tetracycline $250 \mathrm{mg}$. b.d., ferrous sulphate $200 \mathrm{mg}$. t.d.s., and hydrocortisone ointment, and when seen six weeks later her rosacea was completely controlled.

\section{Case 5}

A 42-year-old married woman had suffered from recurrent outbreaks of pustules and redness on the face for 10 years. The recent attack had lasted 10 months, and for the previous six months she had applied betamethasone ointment daily. When seen in January 1968 she had a confluent telangiectasia of the forehead, cheeks, and chin, with the usual atrophic skin which had been seen in earlier similar patients. She was advised to stop using betamethasone, and warned that a rebound flare might occur. Despite the warning she was much distressed when four days after ceasing the applications her face became oedematous and pustular, and the condition became so unsightly she would not leave her home. Tetracycline $250 \mathrm{mg}$. b.d. and hydrocortisone ointment were prescribed, and three weeks afterwards she was much improved. A minor recurrence two months later followed the accidental use of betamethasone ointment for two days.

\section{Case 6}

A 46-year-old steel-worker had suffered from pustulation and erythematous eruption on the cheeks and forehead for six months. He had used fluocinolone ointment once daily until he went on holiday in July 1968. While away he did not use the fluocinolone ointment, and his face became red and swollen. On examination on 1 August 1968 he had a florid rosacea of the forehead, cheeks, and nose, with gross telangiectasia extending into the hair margin. He was treated with tetracycline $250 \mathrm{mg}$. b.d. and $1 \%$ hydrocortisone ointment for five weeks and then tetracycline $250 \mathrm{mg}$. daily for six weeks, by which time his skin had returned to normal.

\section{Case 7}

A 58-year-old woman had suffered from a red pustular eruption on her face for six years. It had not responded to conventional treatment with sulphur applications, and for the previous year she had been treated with betamethasone cream and betamethasone $0.5 \mathrm{mg}$. b.d. When first seen on 30 April 1968 she showed rosacea of telangiectatic type over the face, similar to that seen with overuse of topical steroids. She also had considerable mooning of her face (Special Plate, Fig. 6). It was felt advisable to admit her to hospital to withdraw the systemic steroids. While this was being done the facial eruption became more pronounced despite the concurrent use of oral tetracycline $250 \mathrm{mg}$. b.d. and the application of hydrocortisone lotion, but after a month she had improved. The tetracycline was continued in a dose of $250 \mathrm{mg}$. daily until she was seen on 9 December, when faint telangiectasia of the skin was still present. She had regained her normal facial and bodily contours, and no active rosacea was visible (Special Plate, Fig. 7).

\section{Case 8}

A man aged 60 complained of an erythematous pustular eruption of two months' duration. This had been treated since the onset with fluocinolone ointment daily. Telangiectases were prominent over the cheeks and forehead. Histological examination revealed a normal epidermis but degenerative changes in the collagen of the dermis and dilated blood vessels. Sebaceous glands were increased in size, and an inflammatory infiltrate was present around the blood vessels. His condition improved after tetracycline $250 \mathrm{mg}$. b.d. for 28 days.

Details of the remaining six patients are included in the Table, which gives the particulars of all 14 patients.

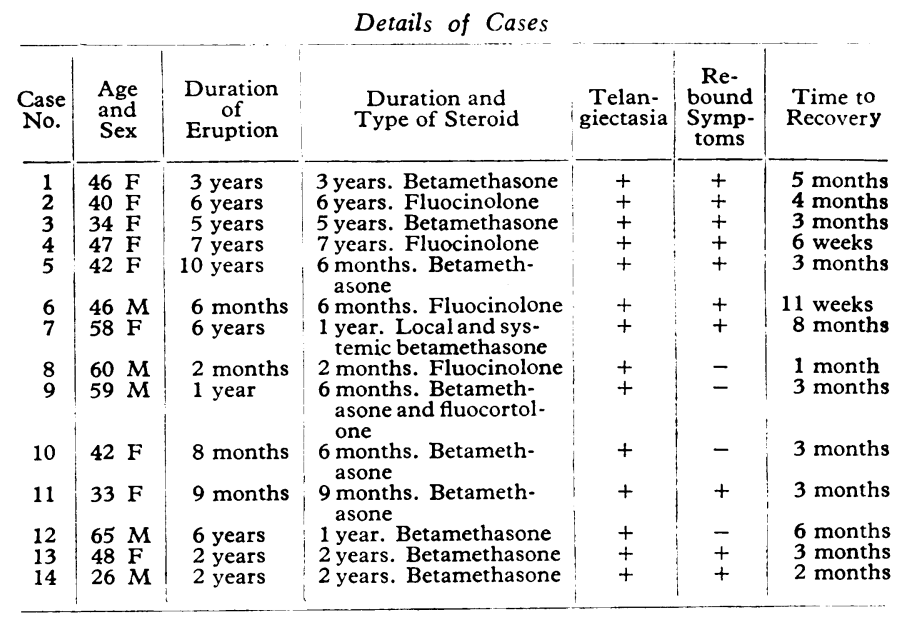

\section{Discussion}

Since Epstein et al. (1963) drew attention to atrophy produced by triamcinolone cream applied to the groins, dermatologists have become more and more aware of the damage to dermal collagen produced by the fluorinated steroids, especially when applied under occlusion. More recently Grice (1966) and Ive and Marks (1968) described the atrophy and telangiectasia of the skin which can mask the presence of fungus infection when this has been incorrectly treated with steroid applications. Thus even in conditions when telangiectasia is not a feature the prolonged application of potent steroids which normally cause constriction of blood vessels (McKenzie, 1962) is followed by the appearance of telangiectasia.

Rosacea is a common condition in this country, its cause remains unknown, and as until recently no reliable method of treatment has existed it is not surprising that the powerful anti-inflammatory steroids should be tried. At first such treatment does suppress pustule formation and diminishes the symptoms of burning, but, as can be seen from the above case histories, prolonged use leads to an increase and extension of the telangiectasia, which is present in at least half the patients with rosacea (Marks, 1968).

Steroid-induced telangiectasia was present in all 14 cases, and could be recognized by its distribution, which extended over the whole area of application of the ointment, often up to the hair line; a pattern which does not occur in rosacea, where the redness is confined to the malar regions, the chin, and the central forehead. In those patients who had applied betamethasone or fluocinolone daily for over three years severe atrophy and spontaneous subcutaneous haemorrhages occurred, comparable with those seen in other dermatoses treated by occlusive techniques. It is presumed that the superficial blood vessels become more visible because of the disappearance of dermal 
collagen, and this is supported by the histological examinations done in Cases 2 and 8, which confirmed that the dermal collagen showed degeneration, though this may occur in untreated rosacea (Marks, 1968).

The shortest duration of treatment required to produce adverse effects was two months, but in most was six months or more. Only one patient (Case 7) had been given systemic as well as topical steroids, and her response was much the same as in the topical steroid group.

Perhaps the most interesting phenomenon was the rebound inflammation when treatment was stopped. This occurred in 10 of the 14 patients, in the main those who had applied steroids for the longest time. Redness, oedema, and extensive superficial pustulation followed within a week of leaving off the treatment.

In some patients this happened by accident because they had left their ointment at home when they went on holiday, and the inflammation was attributed to sunburn. In Case 4 the relation between rebound pustulation and the cessation of application of fluocinolone ointment was not recognized by me over a number of years. The pustules were smaller but more numerous than those usually seen in rosacea and closely resembled the pustular form of psoriasis. Cases 3 and 4 were so severely affected that hospital admission was required. Usually the rebound reaction settled within three weeks, but was reproduced in one patient (Case 5) by the accidental application of betamethasone ointment for two days, when she had almost recovered.

Patients have been treated with oral tetracycline $250 \mathrm{mg}$. b.d. initially, a month later dropping the dose to $250 \mathrm{mg}$. daily. Tetracycline had been found a reliable method of treatment in a previous trial in rosacea (Sneddon, 1966). Sulphur-containing creams and ung. aquosum were substituted as local treatment for the steroids, but better results were obtained with hydrocortisone ointment, which cut down the violence of the rebound reaction, while allowing the atrophic collagen to recover. The majority of patients have been much improved or completely recovered in three months, and it was surprising how rapidly the telangiectasia faded. This can be seen in the illustrations of Cases 2 and Case 7 (Special Plate). Presumably as the collagen increases in the dermis the plexus of blood vessels becomes invisible.

Though betamethasone figured in nine patients, fluocinolone in four, and fluocortolone 21-hexanoate in one, this probably reflects the pattern of local presoribing, and no conclusion can be drawn from the figures.

This study has thrown no further light on the cause of rosacea or on the mode of action of tetracycline, but I feel the conclusion to be drawn is that the fluorinated topical steroids should not be used in the treatment of rosacea, though the less potent hydrocortisone preparations appear harmless.

I would like to thank my colleague Dr. Ronald Church for permitting me to use details of Case 3, and I am grateful to the department of photography, United Sheffield Hospitals, for the illustrations.

\section{REFERENCES}

Epstein, N. N., Epstein, W. L., and Epstein, J. H. (1963). Archives of

Dermatology, 87, 450.
Grice, K. (for F. R. Bettley) (1966). Proceedings of the Royal Society of Medicine, 59, 254.

Ive, F. A., and Marks, R. (1968). British Medical fournal, 3, 149.

Marks, R. (1968). British fournal of Dermatology, 80, 170.

McKenzie, A. W. (1962). Archives of Dermatology, 86, 611

Sneddon, I. B. (1966). British fournal of Dermatology, 78, 649.

Sneddon, I. B. (1968). British Medical fournal, 1, 579.

\title{
Availability of Food Iron
}

\author{
A. JACOBS,* M.D., M.C.PATH. ; D. A. GREENMAN, $†$ F.I.M.L.T.
}

\begin{abstract}
Summary : Iron has been extracted from 25 common foods under conditions resembling those prevailing in the stomach under physiological conditions. In most cases less than half the iron in the foods is released into solution. The soluble iron is mainly in ionizable form, except in the case of meat products and black pudding. The amount of food iron released is influenced by cooking and the presence of iron-binding substances in some foods. The total dietary iron probably does not represent the amount available for absorption.
\end{abstract}

\section{Introduction}

A considerable body of data exists regarding the iron content of foodstuffs but comparatively little is known about the availability of food iron for absorption in the human small intestine. Early work on iron absorption in which the method of chemical balance was used yielded limited information which does not

* Reader in Haematology.

t. Chief Technician.

Department of Pathology, Welsh National School of Medicine, Cardiff. always agree with later results obtained with tracer doses of radioactive iron (Bothwell and Finch, 1962). Chodos et al. (1957), Moore (1964), and Hussain et al. (1965) obtained direct measurements of iron absorption from a limited number of foods into which radioactive iron had been incorporated during the normal growth process. The investigation of a complete diet by this method would be a formidable procedure. Much detailed information has now accumulated about the absorption of ${ }^{59} \mathrm{Fe}$-labelled inorganic iron and haem iron in man. Many workers have followed the suggestion of Pirzio-Biroli et al. (1958) that a tracer dose of ${ }^{59} \mathrm{Fe}$ added to a test meal will mix with iron released from the food during digestion and thus enable the metabolic progress of food iron to be followed. This is true in a qualitative sense, but a quantitative assessment of food iron absorption by this method can apply only to the specific chemical form of radioactive iron added to the meal and only if the amount of iron released from the food in this form, and thus the total intraluminal pool size, is known.

There is little information about the amount or chemical nature of iron released from food during the digestive process. Shackleton and McCance (1936) estimated the amount of ionizable iron in a large number of foodstuffs, and similar estimates, 